\title{
O PAPEL DA FORMAÇÃO INICIAL NO PROCESSO DE CONSTITUIÇÃO DA IDENTIDADE PROFISSIONAL DE PROFESSORES DE EDUCAÇÃO FÍSICA
}

\author{
DR. JOSÉ ÂNGELO GARIGLIO \\ Doutor em Educação pela PUC-Rio e Professor Adjunto do \\ Departamento de Educação Física da Escola de Educação Física da \\ Universidade Federal de Minas Gerais (Minas Gerais - Brasil) \\ e-mail: angelogariglio@hotmail.com
}

\begin{abstract}
RESUMO
Este texto relata os resultados de um estudo que teve como de um de seus objetos de análise a discussão do papel ocupado pelos componentes disciplinares, pedagógicos e práticos, transmitidos durante a formação inicial, no processo de constituição da identidade profissional de três professores de Educação Física.
\end{abstract}

PALAVRAS-CHAVE: Educação Física; formação de professores; identidade profissional. 
Este texto relata os resultados de um estudo que teve como objeto central a descrição e análise do papel ocupado pelos componentes disciplinares, pedagógicos e práticos, transmitidos durante a formação inicial, no processo de socialização profissional de três professores de Educação Física (EF) que atuam numa escola profissionalizante da Rede Federal de Ensino.

Com a pesquisa queríamos compreender melhor qual o peso da experiência formativa com os campos disciplinares no âmbito da formação inicial na veiculação de práticas e de regras de conduta comuns aos membros de uma coletividade: os professores de Educação Física. Tínhamos como hipótese o fato de que a formação inicial, mais do que um tempo de aprendizagem de conteúdos e técnicas de ensino, se constitui num ambiente formativo que delimita zonas de fronteira em relação a outros domínios de conhecimento ou campos disciplinares. Tal projeção ancorava-se na constatação de que parte significativa da constituição dos saberes da base profissional dos professores da educação básica é marcada pelo sentido de pertencimento a um determinado campo disciplinar. Como ressalta Borges (2002) a profissão docente no Brasil sofreu e sofre uma forte orientação disciplinar, tornando-se constituinte dos saberes profissionais, particularmente na identificação com a matéria, na mirada sobre o ensino, na forma como se definem como professores de uma disciplina.

Sobre essa questão Lessard et al. (2003) nos lembram que, o mundo dos professores aparece como uma diversidade ao plano das identidades profissionais afirmadas. Tal diversidade é marcada fortemente pelas condições de trabalho realmente efetuadas pelos diferentes subgrupos de professores, pelas missões educativas específicas e redefinidas por eles. Os professores se constituem na realidade numa multiplicidade de subgrupos com a sua própria identidade, a sua experiência do sistema escolar, vivendo tensões com outros subgrupos e com o quadro institucional.

Feinama-Nemser et al. ( 1998) reforçam a tese de que existiriam, no campo de atuação profissional, não apenas uma, mas várias culturas docentes. Para eles, a cultura profissional pode ser considerada como um conjunto de sentimentos partilhados, de hábitos mentais e de modelos de interação com os alunos, os colegas, os administradores e os parentes. Essa cultura profissional compreenderia também para eles as recompensas intrínsecas, associadas ao exercício do métier.

Esse debate nos instiga a pensar sobre a existência de culturas docentes diferenciadas. Ao lançarem mão do conceito de cultura docente, eles anunciam a existência de formas diferenciadas de saber-ser, saber-fazer e de habilidades pedagógicas peculiares 
a cada subgrupo de professores presente num contexto escolar marcadamente pulverizado (professores de educação infantil, ensino fundamental, ensino médio, educação profissional, de portadores de necessidades especiais e professores dos diferentes campos disciplinares do currículo escolar).

No bojo dessas discussões, situamos nosso objeto de pesquisa ao redor de uma investigação que visa compreender os modelos ou tipos de ação desenvolvidos pelos professores de EF. Estamos entendendo aqui como modelos de ação as representações elaboradas e veiculadas pelos professores de EF a respeito da natureza de sua prática, representações essas que servem para definí-la, estruturá-la e orientá-la em situações de ação. Essas representações são incorporadas à prática e conferem certa inteligibilidade e sentido à atividade educativa, oferecendo aos educadores significações, instrumentos cognitivos de apreensão da realidade, de orientação de condutas, pontos de referência relativos à estruturação do seu comportamento no ambiente do ensino (PERRENOUD, 2000; TARDIF, 2002).

Tendo essa questão como eixo central da análise, buscamos encontrar resposta às seguintes indagações: quais saberes e práticas da formação inicial são tomados pelos nossos sujeitos de pesquisa como válidos para o desenvolvimento de sua prática profissional na escola? Quais eles julgam ter pouco valor e significado? Que tipos de habilidade pedagógica eles entendem que demarcam a sua própria capacidade de ensinar? O reconhecimento da legitimidade da ação profissional dos professores de EF na escola haveria de se dar por qual tipo de capacidade pedagógica? Quais as experiências formativas mais significativas desse período de formação? Quais as disciplinas mais importantes? Quais os professores são lembrados de maneira mais positiva ou negativa? Por quê? Que críticas esses professores fazem da formação inicial? A essas e outras questões tentamos responder recorrendo às vozes dos docentes pesquisados.

\section{TRAJETÓRIA METODOLÓGICA}

O estudo foi realizado com três professores de EF, dois homens e uma muIher, pertencentes ao quadro de docentes de uma escola profissionalizante da rede

I. Para PERRENOUD (200 I), saberes e conhecimento são representações organizadas do real, que utilizam conceitos ou imagens mentais para descrever e, eventualmente, explicar, às vezes antecipar ou controlar, de maneira mais ou menos formalizada e estruturada, fenômenos, estados, processos, mecanismos observados na realidade ou inferidos com base em observações. Para o autor, uma representação funciona como um conhecimento (ou um saber), desde que os que a possuem tenham a "convicção íntima" de ter percebido e compreendido parte da realidade e de poder agir "com conhecimento de causa". 
federal de ensino. Os três docentes investigados não foram escolhidos de maneira aleatória. A escolha foi submetida aos seguintes critérios: ter formação superior, ter mais de dez anos de experiência profissional na área da EF, ter mais de cinco anos de experiência profissional na escola pesquisada, estar submetido ao regime contratual de dedicação exclusiva e pertencer ao quadro efetivo da escola.

Levamos em consideração aqui a classificação desenvolvida por Huberman ( 1992 ) sobre o ciclo de vida profissional de professores. Nessa direção, os professores pesquisados estão enquadrados dentro da fase do ciclo profissional que Huberman denomina de diversificação. Nessa fase, os professores se lançariam a uma série de experiências profissionais, diversificando o material didático, o modo de avaliação, a forma de agrupar os alunos e as sequências do programa.

No desenvolvimento da pesquisa utilizamos o recurso da entrevista como forma de acesso à realidade projetada. A entrevista nos possibilitou revelar a complexidade singular das ações e reações dos nossos sujeitos de pesquisa em um contexto educacional específico: a formação de professores de educação física. A respeito dessa questão, cabe ressaltar a discussão sobre a entrevista compreensiva desenvolvida por Kaufmann ( 1996). Para ele, a entrevista não se limita apenas a colher informações sobre uma realidade. O entrevistado, ao se engajar e se entregar no momento da entrevista, desenvolve intenso e profundo trabalho sobre si mesmo para construir sua própria identidade, assim como a realidade social à qual está inserido. Para esse autor, numa entrevista o pesquisador deve-se convencer de que ele ocupa posição de observação privilegiada, na tomada direta sobre a construção da realidade através da pessoa que fala à sua frente. Becker (1992) ratifica a importância da entrevista numa pesquisa de cunho sociológico, quando nos lembra que a demarcação da diferença entre a opinião particular e a comunicação pública pode fornecer indicações importantes das normas e regras de determinado grupo social.

Na busca da compreensão dos relatos dos professores é importante lembrar que a recordação do que já se viveu foi tomada na pesquisa mais como uma reinterpretação do que uma reprodução do passado. Os professores, ao entrarem no trabalho de recontar a sua história pessoal, buscam dar ordem e sentido ao passado em função do que vivem no presente. Melhor dizendo, são as questões da prática profissional que ajudam a selecionar os fatos mais significativos da história de sua relação com o universo da docência (HUBERMAN, 1995; FONTOURA, 1995).

\section{OUVINDO AS VOZES DOS PROFESSORES}

Fazendo um balanço com base nas respostas apresentadas pelos professores entrevistados, é possível identificarmos alguns níveis de apreciação da formação 
inicial: o distanciamento da formação inicial da realidade do trabalho na escola; as aprendizagens extracurriculares experienciadas em atividades profissionais paralelas dentro da Universidade; a aprendizagem dos saberes práticos advindos dos estágios de formação; a relação tensa com o campo da pedagogia e as relações positivas ou negativas com determinados professores da graduação.

Inicialmente foi interessante perceber que, quando são formuladas as questões sobre quais seriam os saberes necessários ao ensino, apreendidos durante a formação inicial, os professores selecionam lembranças que remetem à postura de determinados professores, seja na forma como conduzem a relação professoraluno, seja como elaboram os processos de avaliação, seja como desenvolvem suas metodologias. Tais lembranças realçam, dessa maneira, mais a postura, o comportamento e o fazer pedagógico do que propriamente os conteúdos ensinados. Vejamos o relato abaixo:

A professora que dava aula de dança, ela usava aquele espaço da dança para até trabalhar conosco a questão corporal, essa questão de reconhecer o próprio corpo e dar liberdade ao outro de conhecer o corpo também. Só que para um estudante de Educação Física, no início, foi um choque. Tinha muita gente na minha turma que era atleta ou ex-atleta, e que entrou com esse objetivo, por isso batia de frente com ela nessas questões. Como não era a minha trajetória, eu nunca fui atleta, não entrei como ex-atleta, para mim que sempre gostei de dança, para mim foi mais tranquilo, mas lembro dela como um desafio. (Profa. Márcia)

Como havíamos dito essa professora foca mais especificamente o saberfazer de seus professores formadores, do que propriamente os conteúdos por eles transmitidos. São destacados aqui o cuidado com a relação professor-aluno, as práticas educativas preocupadas em atingir a subjetividade dos alunos e sua formação humana. Assim, são distinguidas determinadas aprendizagens e saberes que os municiariam de habilidades necessárias para intervir profissionalmente na escola. Essas habilidades seriam aquelas que os capacitariam para uma ação pedagógica dotada de uma relação mais sensível com os alunos, mais preocupada com a forma e com a metodologia de ensino e com os exemplos de conduta de seus professores formadores.

No entanto, o Prof. Mauro, quando Ihe foi colocada a questão sobre o que teria ficado de mais importante e positivo desse período formativo na graduação, relata que foi a possibilidade de ter tido um contato mais longo e profundo com o conhecimento acerca do esporte. Vejamos o seu relato:

A questão técnica eu utilizo nas aulas e entendo que isso traz resultados. Porque a partir daí é que eu consegui entender e discernir o que isso significa no contexto do domínio da técnica. Das possibilidades de dominar tecnicamente o conteúdo, como professor de 
Educação Física, como professor na formação dos alunos de maneira geral, do meu papel. De ajudar nessa formação da relação com o outro. Ajuda muito. E entendo ser ali uma base de sustentação para mim, com toda a experiência que eu deixei levar durante esse período, para agir, para tomar decisões, eu acho que a vertente do esporte é uma vertente que me possibilita estar ampliando a discussão desse esporte, de estar dando tratamento de uma situação da formação do aluno crítico, da relação com o outro, na discussão com o próprio conteúdo do esporte. Acho que o fato de você dominar mecanicamente te dá condições de trabalhar isso, de perceber isso de maneira mais fácil, de entender como que eles se inter-relacionam. Como eles se entrelaçam nessa relação. (Prof. Mauro)

Mesmo reconhecendo que o curso se pautou pela ênfase no treinamento esportivo, voltado quase que exclusivamente para preocupações circunscritas ao ensino da técnica do movimento esportivo, esse docente reconhece que o conhecimento aprofundado sobre o conteúdo esporte o municiou de boas condições para melhor adaptar e transformar esse conhecimento em função das necessidades que ele apregoa como centrais para a sua intervenção pedagógica. Nesse campo de ações, são destacadas determinadas potencialidades do ensino do esporte que seriam favoráveis, por exemplo, à promoção de práticas educativas que pudessem intervir na forma como os alunos conduzem suas relações coletivas.

Já o Prof. Leandro, ao relacionar suas lembranças mais significativas da formação inicial, acaba por rememorar sua experiência com a professora de didática do ensino de Educação Física. Eis as suas observações:

D. Nízia era fantástica, fantástica, uma tia legal demais. Primeiro pela maneira dela lidar com a gente, o carinho que ela tinha com a gente. É a questão do trato, da relação, a paciência, ela não deixava você cair no erro, ela percebia, ela tinha uma maneira muito especial de conduzir as coisas. Estava na faculdade, mas ela não deixava perder de vista aquela coisa, vamos dizer assim, lá do ensino fundamental. Mais em função disso, eu aliei a teoria à prática no momento mesmo. Justamente, e disso é que eu ia gostando cada vez mais, do conteúdo abordado por ela, a minha participação era outra nas atividades dela. (Prof. Leandro)

Esse docente, ao centrar seus relatos mais positivos desse período de formação no contato estabelecido com sua professora, estaria revelando que esse se constituiu em experiência formativa marcante, uma vez que estava recheado de conteúdos afetivos que seriam, segundo ele, muito próximos das relações pedagógicas presentes no âmbito do ensino fundamental.

Ainda nesse relato, ao apontar que nessa disciplina ele pôde experienciar maior diálogo entre a teoria e a prática, ele nos parece dizer que esse diálogo não se deu apenas porque a disciplina no caso era de didática. A presença da afetividade, do carinho e da atenção demonstrados pela professora dentro de sua prática 
pedagógica no ensino dessa disciplina possibilitaram a materialização do diálogo mais rico entre a teoria e o que seria a prática profissional no universo de atuação na EF. Portanto, saber ensinar sem perder de vista o trato mais humano, o cuidado com a relação mais afetuosa, seria um saber tomado por esse docente como fulcral para o desenvolvimento de ações pedagógicas no ensino da EF.

Na mesma linha, os docentes Mauro e Leandro, ao relatarem algumas de suas experiências em estágios dentro da escola ou mesmo fora dela, centram suas lembranças de forma a salientar a positividade da relação afetiva estabelecida com os alunos. Eis o relato sobre essas vivências:

\begin{abstract}
Eu trabalhei durante seis meses no estágio com alunos muito carentes, era quase que uma escola de aplicação dentro da Universidade, e nós tivemos situações de aula com esse grupo, que não tenho condição de mensurar, mas que foram fatos que mudaram visivelmente para mim, e sentimentalmente, não só a minha relação com os meninos, mas deles entre eles e com a escola, a ponto de os professores estarem conversando com a gente, éramos dois professores, a diretora sempre chamava, e perguntava o que a gente estava lendo, estudando, porque os meninos tinham mudado muito num período de seis meses; aquilo balançou demais. $\bigcirc$ acontecido bateu muito forte na questão do sentimento, do desejo, do coração mesmo, da relação com os alunos, por conta da situação que ocorreu, e aquilo começou a me sensibilizar um pouco mais para a questão da disciplina, da parte pedagógica, da aula em si. (Prof. Mauro)
\end{abstract}

Entendendo que a experiência prática pode vir anteriormente à entrada no universo profissional e que essas experiências já antecipam certa ambientação do que seria o modus vivendi ou o modus operandi da prática profissional (BORGES, 2002), podemos constatar que o relato acima demonstra que os estágios da prática de ensino da Universidade já se haviam constituído em momentos do que seria o universo singular de intervenção pedagógica do professor de Educação Física.

No relato do Prof. Mauro, é salientado que o estabelecimento de relações mais afetivas com os alunos se apresentou como estratégia central para que ele pudesse atingir seus objetivos educativos. Também que o reconhecimento de suas habilidades pedagógicas pelos demais atores escolares se deu muito em função da mudança significativa do modo de agir e de se comportar, demonstrado pelos alunos após o término do estágio.

Manifestam-se, aqui, fortes elementos do que os professores de EF entrevistados reconhecem como as habilidades e os saberes pedagógicos que confeririam a esses docentes o reconhecimento de sua capacidade de ensinar, a ver: capacidade de minimizar determinados tipos de sofrimento vividos por alunos oriundos de contextos distintos e que são vítimas de problemas sociais ou comportamentais, proporcionando-lhes momentos de alegria e prazer; habilidade para intervir nas 
relações coletivas, nas atitudes; capacidade de agir por meio de atitudes afetivas e carinhosas, dentre outras. ${ }^{2}$

Sobre esse ponto é interessante percebermos que os nossos professores pesquisados, mesmo tendo sua inserção profissional numa escola de ensino médio profissionalizante, de certa forma, relativizam conclusões de outras pesquisas que apontam que o caráter "maternal" ou afetivo do ensino estaria mais presente em escolas de ensino fundamental ou restrito ao universo de atuação docente feminina. Assim, a cultura do cuidado (CARVALHO, 1998) não se apresenta em contraposição às dimensões da instrução. Ao contrário, ela é um componente importante no processo de elaboração das práticas de instrução dos professores. A noção de profissionalismo não aparece descolada dos aspectos afetivos do exercício da docência, mas colocada numa posição de relevo em relação aos aspectos técnicos. Mais do que isso, a cultura do cuidado surge como um componente positivo que harmoniza a identidade profissional desses docentes.

Paralelamente, ao citar a disciplina de recreação, da qual foi monitor durante a Faculdade, o Prof. Leandro também nos vai proporcionar mais um elemento que aponta para o reconhecimento de determinados saberes da formação inicial que teriam sido importantes para a sua intervenção educativa na escola. $\bigcirc$ contato mais aprofundado com esse conteúdo o habilitou de técnicas didáticas de como tratar esse conteúdo no âmbito do ensino, como também o contato mais intenso com os jogos e a recreação teriam contribuído para sensibilizá-lo ainda mais para intervenções educativas. Tal contato com o conteúdo de jogos e recreação parece ter reforçado ainda mais o entendimento do que seria função da EF e de seus professores - saber-ensinar referenciado por experiências de gratuidade, de alegria e de lazer. Isso parece reforçar a hipótese de que os professores de EF se reconhecem como profissionais capazes de ensinar na escola, sem perder de vista as dimensões estéticas da aprendizagem dos conteúdos. Vejamos o que ele nos diz sobre esse ponto:

Era a própria D. Nízia quem dava recreação e jogos, que era uma disciplina; já prática de ensino era outra, coisas distintas com o mesmo professor. E eu fui monitor da prática de ensino, só que ela pedia em relação ao aluno, que eu levasse para a vida prática a questão

2. BORGES (2002), em seu estudo com docentes dos diferentes campos disciplinares de $5^{\mathrm{a}}$ a $8^{\mathrm{a}}$ séries do ensino fundamental, mostra que os conhecimentos que os professores de EF apontam como relevantes ao seu trabalho foi o domínio de conhecimentos relativos às relações interpessoais. Nessa linha, eles colocam em destaque os conhecimentos adquiridos no campo da psicologia, seja no tempo da formação inicial, seja em estudos ou cursos realizados durante o percurso da formação continuada, como fundamentais à sua ação pedagógica na escola. 
de recreação e jogos, como, exemplo, se a gente está aqui, isso é um ponto de partida para recreação e jogos. Ela dizia que podíamos usar muita coisa nas aulas. Foi marcante. (Prof. Leandro)

Ainda no sentido do reconhecimento de quais seriam os saberes e as habilidades apreendidos durante a formação inicial e tomados como significativos para o exercício da profissão dentro da escola, vale citar que dois dos três professores relatam o quanto foi importante a experiência de ter podido trabalhar, ainda como estudantes na Universidade, em atividades de organização de eventos esportivos. Para um deles, essa oportunidade foi tomada como uma experiência verdadeiramente profissional; para a outra docente, esse trabalho foi de suma importância para o desenvolvimento de atividades extraclasse dentro da escola. Observemos o que a professora nos relata:

Realmente foi uma experiência interessante estar na LUVE³. Eu acho que hoje ela até está presente em algumas coisas que eu faço, principalmente quando eu tenho que organizar algum evento esportivo. Essa parte de organização de eventos, nisso eu acho que contribuiu muito. Mas foi importante, muito, com certeza. (Profa . Márcia)

Nesse relato, a Profa. Márcia nos revela alguns dos saberes que parecem ter sido fundamentais para o desenvolvimento do seu trabalho na escola. São conhecimentos que possibilitam operar com práticas que mobilizam grande número de pessoas, envolvem grupos, possibilitam pensar a ação pedagógica para além do processo de ensino-aprendizagem dos conteúdos especíicos da matéria, levados a efeito no espaço circunscrito da escola. Dentre esses saberes pedagógicos a Profa . Márcia destaca que a habilidade de organizar eventos se constituiu um saber muito importante para o seu reconhecimento profissional dentro da escola.

Além disso, ao reconhecerem o valor positivo dessa experiência durante a graduação, esses professores parecem-nos dizer que existe uma fundamental relação entre o trabalho docente específico da EF e o todo da vida institucional. Essa relação parece constituir-se em um diferencial da ação pedagógica deles dentro da escola, ou seja, uma ação que se projeta para atingir a totalidade da vida social da escola.

Ainda na busca do reconhecimento dos saberes docentes que vão sendo edificados por eles desde a sua formação inicial, que os orienta e ajuda a se moverem dentro da vida escolar, passamos agora a analisar como eles vêem as suas relações com os saberes da área pedagógica.

Os professores Mauro e Márcia experimentaram uma formação acadêmica estruturada no famoso sistema três mais um, isto é, três anos cursando as disciplinas

3. Liga Universitária Esportiva. 
específicas e um ano cursando as disciplinas da licenciatura. Esses dois docentes fazem críticas severas a esse sistema ou a maneira como a Universidade lidava com esse modelo de formação. Fica nítido em seus relatos certa distância e a incompatibilidade entre os saberes pedagógicos ministrados na Faculdade de Educação e a especificidade pedagógica da EF. Vejamos os conteúdos dos seus relatos acerca dessa temática:

As disciplinas da Educação, que eram Psicologia, Sociologia, Estrutura, eram muito mal feitas, muito ruins. Nós não gostávamos, nós tínhamos professores excelentes, mas não levávamos muito a sério, até por conta dessa influência do curso. Acho que mesmo com a questão técnica em voga, em ênfase, nós tínhamos que ter no mínimo um direcionamento, pelo menos uma referência, uma orientação quanto à necessidade e à importância disso no contexto, e isso não aconteceu. A formação pedagógica foi ruim, mesmo na licenciatura. Porque nós não nos envolvíamos com ela. As disciplinas pedagógicas eram bem reduzidas. Nós fizemos para a licenciatura cinco disciplinas, quatro ou cinco, sendo duas optativas. Optativa ninguém fazia, de jeito nenhum, muito raro. (Prof. Mauro)

Tal como evidenciaram algumas análises acerca dos problemas verificados nos cursos de licenciatura nas últimas décadas no Brasil (LUDKE, 1994), Bacharelado e Licenciatura marcharam por vias diferentes, com objetivos claramente distintos e com pouca ou quase nenhuma integração entre si. Geralmente essas duas formações se passam em departamentos ou unidades da Universidade, distantes umas das outras, tanto física quanto simbolicamente, não existindo nenhuma relação das disciplinas da formação disciplinar ou específica com as disciplinas de formação pedagógica e a prática; os professores universitários que atuam nessas diferentes áreas não se encontram e tampouco estabelecem intercâmbios; os alunos, na maioria dos casos, deslocam-se de uma unidade a outra, buscando preencher os seus créditos e prérequisitos, para obtenção do título.

Assim, os nossos professores relatam que o distanciamento já comentado entre a formação específica e a formação pedagógica não ficava restrito ao âmbito dos conteúdos, indo ao âmbito do ambiente formativo. É citada como questão fundamental a existência de um clima institucional mais agradável, mais afinado com o tipo de ambiente que seria específico ao ensino da Educação Física. É como se o Centro de Educação Física tivesse uma personalidade própria, que o caracteriza e que formaliza os comportamentos dos seus membros, detentor de um clima organizacional que é percebido ao mesmo tempo de uma forma consciente e insconsciente, por todos os atores deste sistema social, tal como o clima atmosférico que nos afeta, sem que necessariamente estejamos ao corrente da sua composição (BRUNET, 1992). A profa. Márcia nos descreve esse sentimento de maneira muito clara: 
Nós fazíamos essas disciplinas junto com alunos de Veterinária, Biologia, e não havia essa ligação. Parecia que nesse momento nós estávamos em outra Universidade. Quando nós íamos para a área de Educação Física, aí sim, nós nos vestíamos de estudantes de EF. E isso deixava bem distinto o que era a Educação Física e o que não era o curso de Educação Física na época. Quando nós saíamos daquelas disciplinas que não faziam parte propriamente do "curso de Educação Física", a gente entrava então, incorporava o personagem do aluno de Educação Física, que era aquele que se vestia de bermuda, podia andar de forma mais soltinha pela Universidade. A gente não podia assistir a aula com aquela indumentária que às vezes era própria da EF. Viçosa é muito quente, o professor não permitia que os meninos fizessem aulas de camiseta, mas as meninas podiam, tem sempre essas coisas assim, que é de mulher, o que é roupa de homem, essas coisas. Mas, por exemplo, a gente andava às vezes de chinelo porque tinha aula de natação e tudo, para assistir a aula de chinelo o professor entendia aquilo como um deboche, essas coisas, então isso era um problema. Quando a gente estava naquele Departamento de Educação Física o ambiente era diferente, a forma de lidar com tudo, o relacionamento com as outras pessoas, parece que era um ambiente muito fora do acadêmico e muito mais no pessoal mesmo, talvez pela afinidade com o curso, esse é o meu ambiente, talvez a gente ficasse um pouco mais à vontade realmente. Parecia que tudo ali corria numa forma muito mais tranquila do que fora daquele ambiente da Educação Física. (Profa. Márcia)

Essas reflexões contidas no discurso da professora Márcia apontam para a consideração da cultura institucional como objeto de reflexão em estudos sobre a formação nas licenciaturas, ao permitir outra "visibilidade" da dimensão formativa presente na diversidade dos contextos educacionais e nas situações de trabalho que neles emergem. Essa visão do ambiente institucional como um contexto "globalmente formativo" para o conjunto dos seus habitantes abre possibilidades interessantes de análise sobre a totalidade das experiências formativas vividas por alunos e professores no interior da vida institucional das escolas de Educação Física. Os processos de formação de professores formadores e estudantes aparecem referidos, a um mesmo espaço organizacional, a um mesmo tempo (aprendizagens por interações recíprocas), aos mesmos princípios. (CANÁRIO, 1996).

Os discursos proferidos pelos nossos sujeitos de pesquisa reforçam, também, o que as pesquisas sobre a formação de professores no Brasil vêm apontando sobre a relação entre os centros específicos de formação e as faculdades de educação, ou seja, que o eixo da formação para a licenciatura deve ser invertido. Com base no conteúdo específico, e em íntima relação com ele, é que o tratamento pedagógico deve ser dado. Parte-se do conteúdo específico para trabalhar a dimensão pedagógica em estreita relação entre eles. Aponta-se que a liderança deve ser da área específica, em profunda colaboração com as unidades de educação. (CANDAU, 1997)

Para além dessa constatação, a docente Márcia nos mostra que, já na Universidade, são criados vários constrangimentos e preconceitos em função de determinado 
comportamento, do modo de vestir e de hábitos manifestados pelos estudantes de EF, tidos talvez, pelo ambiente universitário, como não muito "acadêmicos". Tal fato reforçaria a crença, por parte dos professores de EF, de que os saberes do seu campo disciplinar seriam de um estatuto inferior. Essa docente parece querer-nos dizer que o lugar ocupado pela EF na hierarquia dos saberes escolares - um lugar inferior - e o sentimento negativo que os próprios professores de EF e os demais das outras disciplinas portam em relação a essa disciplina - em função de que essa não dependeria de uma competência intelectual ou por estar mais ligada ao universo do lazer - seria uma representação acerca do papel pedagógica da EF construída, ainda, nos meandros da formação dentro da Universidade.

Levantamos a hipótese de que o sentimento nutrido pelos professores de EF de que sua ação pedagógica estaria mais voltada para os aspectos educativos do que para a instrução ocorreria, em parte, motivado por vivências que, desde a formação inicial, vão informando os professores de EF que os saberes de sua disciplina seriam inferiores ou não "acadêmicos". Caberia a eles dentro da escola, portanto, o papel de educar e não o de ensinar. ${ }^{4}$

O relato da Prof ${ }^{\mathrm{a}}$. Márcia mostra, ainda, que o distanciamento entre o universo da formação específica e o universo da formação pedagógica não se limita à inadequação no tratamento dos conteúdos. Existe todo um contexto ambiental (o ambiente físico da escola de EF) e relacional (a forma de relação e interação entre os alunos, proporcionada, entre outros motivos, pelo tipo de conteúdo ministrado no currículo do curso) que parece reforçar o entendimento, por parte dos nossos professores de EF, de que o universo de intervenção pedagógica da EF se diferenciaria do que seria o "acadêmico".

Mais do que isso, o relato dessa professora mostra-nos uma sensibilidade maior a um universo de formação existente no interior da formação inicial, que transcende a relação de ensino-aprendizagem restrito ao tempo destinado à transmissão de conteúdos. Ela nos estaria alertando para a importância de determinado tipo de ambiente físico, de tempos de formação e de espaços de relação que são tão significativos quanto os conteúdos disciplinares, para a conformação de sensibilidades acerca do que seja a especificidade da ação educativa na escola.

4. Algumas pesquisas sobre a formação inicial e a identidade profissional de professores de EF vêm mostrando que muitos estudantes, durante o período de graduação, tendem a valorizar o curso por meio da ênfase dada às disciplinas do campo biomédico. Eles agiriam em busca de determinado status acadêmico que, segundo os estudantes, estaria mais agregado ao conhecimento científico presente nas disciplinas de cunho biológico (MORENO, 1997; FIGUEIREDO, 200 I). 
No que tange aos processos de formação inicial e seu papel na constituição do idioma pedagógico dos professores de EF pudemos perceber que, não obstante às críticas operadas pelos nossos professores à sua formação universitária, devido ao distanciamento desta em relação às questões e aos problemas oriundos da prática, eles reconhecem a importância da teoria, dos conhecimentos e procedimentos acadêmicos para a sua inserção no universo da prática profissional na escola. Eles criticam a instituição formadora, o que não é o mesmo que negar o papel da teoria, mas simplesmente a impropriedade com que essa foi oferecida nos cursos que frequentaram.

Nossos depoentes nos mostraram que o conhecimento da formação acadêmica foi de suma importância para que eles enfrentassem o "choque da realidade". Diante da complexidade inerente ao contexto de ensino, a formação universitária serviu como espécie de salvo-conduto provisório, necessário para "sobreviver" diante dos turbulentos primeiros anos de sua inserção na vida profissional. Mais do que isso, os conhecimentos acadêmicos aparecem como fundamentais para que, passados os momentos mais críticos vividos ainda nos primeiros anos do magistério, eles possam se tornar substrato básico fundamental para investimentos pedagógicos mais ousados e mais complexos.

Ao criticarem a impropriedade da formação acadêmica perante os desafios colocados pela prática profissional na escola, os professores o fazem de forma a mostrar que a disciplina escolar Educação Física pouco tem a ver com a Educação Física área do conhecimento. A formação para o ensino encoraja uma dissociação entre a disciplina "savante" ou prática social instituída de um lado e a disciplina escolar de outro (PERRENOUD, 2000). Não há, portanto, espaço na formação inicial, para tratar a Educação Física escolar como produção sui generis, que, por um lado, se relaciona com os conhecimentos acadêmicos, mas, por outro, distancia-se desses ao incorporar a força interventora da forma escolar. Não há espaço para ver a EF como "entidade cultural" (CHERVELL, 1990) sui generis produzida pela escola, para a escola e com a escola.

Apontam como outra impropriedade da formação inicial o descuido dos professores formadores quanto ao trato e ao cuidado com as suas próprias tecnologias de ensino. Eles cobram desses profissionais o mesmo desvelo que eles demonstram ter com a interação com os alunos, com a formação dos valores e com suas estratégias de ensino. Como bem lembra Tardif (2000), todo professor, ao escolher ou privilegiar determinados procedimentos para atingir seus objetivos em relação 
aos alunos, assume uma pedagogia, ou seja, uma teoria de ensino-aprendizagem, embora se manifeste com frequência uma pedagogia sem reflexão pedagógica. Essa afirmação permitiria invalidar a crença de certos professores (principalmente os da Universidade) que pensam não estar fazendo uso da pedagogia, simplesmente porque retomam rotinas repetidas há séculos.

Muito mais do que a impropriedade com que a teoria é tratada na formação inicial, nossos depoentes nos alertam para o fato de que a forma ou o como os professores universitários ensinam é tomado como conteúdo da formação. Nos relatos dos professores, a formação universitária foi rejeitada porque os professores formadores negligenciavam a centralidade da dimensão interativa na relação com os alunos, seja individualmente, seja coletivamente. A impropriedade da formação universitária residia no fato de que os professores formadores não se viam como educadores e, portanto, não se apresentavam como exemplos de conduta profissional a serem seguidos. Em quase todos os exemplos que nos foram dados sobre o caráter positivo acerca dos professores formadores e/ou de suas práticas de ensino, foi enfatizada pelos nossos depoentes a dimensão afetiva no trato com os alunos, a sua capacidade de interação com eles, o cuidado com a transposição didática dos conhecimentos acadêmico-científicos para o contexto específico de ensino e a preocupação desses docentes com a formação humana dos estudantes. Eles nos alertam sobre o fato de que a formação inicial restringe por demais a ação docente à função de "ensinantes" e frequentemente esquece suas dimensões formadoras.

Atrelado às relações de aprendizagem das dimensões formadoras, pudemos perceber que o contato com a cultura acadêmica foi fundamental para que os nossos professores pudessem reforçar algumas crenças e representações acerca do papel a ser cumprido pela EF na escola, assim como das funções atribuídas aos seus professores. Ao relatarem o seu desconforto diante do ensino ministrado na Faculdade de Educação, eles procuram demonstrar o descompasso existente dentro da própria Universidade entre o campo pedagógico e o universo de ensino situado da EF. Esse desconforto foi manifestado em vários momentos nos relatos dos nossos depoentes, quando esses descrevem a incompatibilidade do espaço físico destinado ao ensino, o descompasso das metodologias utilizadas pelos professores em relação ao contexto de ensino específico da EF e a distância com que os temas relacionados ao campo da educação eram tratados no que diz respeito ao universo de ensino situado dessa disciplina.

Com isso, os nossos informantes parecem dizer-nos que, desde a formação inicial, a sua profissionalização docente é orientada pelo campo disciplinar próprio da EF. Essa formação contribui para constituir seus saberes docentes, particularmente na identificação com a sua matéria de ensino, no olhar sobre o ensino e na 
forma como se definem como professores dessa disciplina escolar. O rechaço aos conhecimentos da formação pedagógica, à forma de ensinar e aos ambientes de ensino da faculdade de educação são obstáculos importantes à incorporação dos conhecimentos da área pedagógica. Conhecimentos esses fundantes a formação de professores que pretendem atuar da educação básica. Os três professores pesquisados no nosso estudo estão, a sua maneira, nos dizendo que o eixo central da formação inicial deveria ter como primado a área específica. É a partir do conteúdo específico, e em íntima relação com ele, que o tratamento pedagógico deve ser trabalhado. A competência de todo e qualquer professor é o domínio do conteúdo específico (CANDAU, 1997).

No entanto, os dados analisados pela nossa investigação mostram que devemos ir além dessa assertiva. $\bigcirc$ domínio do conteúdo específico não pode ficar restrito às bases metodológicas, epistemológicas ou da compreensão do seu objeto de estudo. À compreensão da sua lógica interna e o seu tratamento pedagógico na escola devem estar relacionados às demais dimensões constitutivas daquilo que chamamos de disciplina escolar: um conjunto de saberes, de posturas físicas e/ou intelectuais, de atitudes, de valores, de códigos e de práticas. Nesta linha, pensar a formação para a licenciatura é pensar, também, a potencia formativa contida na totalidade dos sentidos e significados produzidos pela lógica interna de cada disciplina escolar. Essa totalidade de sentidos, códigos e práticas parecem ser naturalizados e incorporados à identidade profissional dos nossos sujeitos de pesquisa de uma forma pouco reflexiva. Soma-se a isso, o fato de que os professores formadores parecem não ser dar conta dessas práticas de significação produzidas pela cultura universitária. $\bigcirc$ resultado parecer ser a restrição do horizonte de intervenções desses sujeitos no ambiente escolar.

Desde a formação inicial os professores pesquisados se vêem envoltos às questões relacionadas às hierarquias dos saberes escolares (hierarquias entre o campo da educação e o da EF), às diferenças entre os ambientes físicos inerentes às distintas unidades de ensino (escola de Educação Física e Faculdade de Educação), às suas formas peculiares de vestimenta, dentre outras. Essas peculiaridades da formação acadêmica parecem ser tão importantes para a constituição das representações pedagógicas dos nossos professores em relação ao papel da EF quanto os conhecimentos transmitidos pelo currículo formal. Na formação universitária, portanto, engendram-se ou perpetuam-se sensibilidades, disposições, crenças acerca do tipo de intervenção pedagógica destinada aos professores de EF na escola, sensibilidade essa fundamental para a constituição de certezas sobre a sua prática docente.

Ao levantarem as suas críticas em relação à formação oferecida pela Faculdade de Educação, esses professores não estão, a nosso ver, rejeitando de forma 
definitiva os conhecimentos produzidos no campo da educação. Eles nos parecem mostrar que os conhecimentos engendrados na educação devem ser atualizados em razão dos temas e dos desafios advindos de um exercício profissional na escola, composto por um conjunto de especificidades. Com isso, eles demonstram concordar com Bracht (2002), que nos diz que é preciso transformar o nosso "quintal" no "quintal" da pedagogia ou, ainda, a pedagogia nos assumir no seu quintal, mas não com base numa visão reduzida de alguém que vem defender ou vender o seu peixe para sobreviver (ter uma sobrevida), e sim como alguém que quer gestar o campo pedagógico como um todo com contribuições originais. Para esse autor, é preciso desafiar o campo pedagógico com novos problemas e temas, sem o receio de "perder" a identidade.

The Role of Undergraduate Study in the Constitution of the Professional constitution of the Professional Identity of Physical Education Teachers

ABSTRACT: This paper presents the results of a research whose one of its aims was to analyze and discuss the role of curricula components, pedagogic and practical, taught in the undergraduate studies, in the constitution process of professional identity of three Physical Education teachers.

KEYWORDS: Physical education; teachers' training; professional identity.

\section{El rol de la formación inicial en la constitución de la identidad profesional de profesores de Educación Física}

RESUMEN: El texto presenta los resultados de un estudio que tuvo como uno de sus objetivos el análisis y la discusión del rol ocupado por los contenidos disciplinares, pedagógicos y prácticos, transmitidos durante la formación inicial, en el proceso de constitución de la identidad de tres profesores de Educación Física.

PALABRAS CLAVE: Educación física; formación profesional de profesores; identidad profesional.

\section{REFERÊNCIAS}

BECKER, H. S. Métodos de pesquisa em Ciências Sociais. São Paulo: Editora Hucitec, 1994. BRACHT, V. et al. A prática pedagógica em Educação Física: a mudança a partir da pesquisaação. Revista Brasileira de Ciências do Esporte, Campinas, v. 23, n. 2, p. 7-212, jan. 2002. 
BRUNET, L. Clima de trabalho e eficácia da escola. (Org.) In: NÓvOA, António (Org) As organizações escolares em análise. Lisboa: Dom Quixote, 1992. p. 121-138.

CANÁRIO, R. O estudo sobre a escola: problemas e perspectivas. In: BARROSO, J. (Org.). O estudo da escola. Porto: Porto Editora, 1996. p. |2| - | 5 |.

CANDAU, V. M. Universidade e formação de professores: que rumos tomar? In: Magistério: construção cotidiana. Petrópolis: Vozes, 1997. p. 30-50.

CARVALHO, M. P. Gênero e trabalho docente: em busca de um referencial teórico. In: BRUSCHINI, C.; BUARQUE, H. H. Horizontes plurais: novos estudos de gênero no Brasil. São Paulo: FCC, 1998. p. 64-89.

CHERVEL, A. História das disciplinas escolares: reflexões sobre um campo de pesquisa. Educação e Realidade. Porto Alegre, n. 2, p. 177-229, 1990.

FIGUEIREDO, Z. C. C. A formação docente, currículo e saber. In: CAPARROZ, F. E. Educação Física escolar: política, investigação e intervenção, v. I. Vitória: Proteoria, 200 I . p. I 15-139.

FEIMAN-NEMSER, S.; FLODER, R. E. Cultural aspects of teaching. In: WITTOCK, M. C. (Dir.). Handbook of research on teaching. $3^{\text {rd }}$. edition, p. 505-526). New York: Macmillan, 1986.

FONTOURA, M. M. Fico ou vou-me embora? In: NÓVOA, A. Vidas de professores. Porto, Porto Editora, 1995. p. 17|-198.

HUBERMAN, M. O ciclo de vida profissional dos professores. In: NÓVOA, A. Vida de professores. Porto: Porto Editora, 1992. p. 31-62.

KAUFMANN, J. C. L'Entretien comprehensive. Paris: Éditions Nathan, 1996.

LESSARD, C; TARDIF, M. Les identities enseignantes: analyse de facteurs de différenciation du corps enseignant québécois 1960-1990. Montreal, Editions du CRP, 2003.

LUDKE, M. Avaliação institucional: formação de docentes para o ensino fundamental e médio nas licenciaturas. Relatório de pesquisa apresentado ao Conselho de reitores das universidades Brasileiras (CRUB), 1994.

MORENO, A. Educação Física: de que profissão e de que profissional se fala? In: FRANCO, C.; KRAMER, S. Pesquisa e educação: história, escola e formação de professores. Rio de Janeiro: Ravil, 1997. p. 257-275.

PERRENOUD, P. Lê role de la formation à l'enseignement dans la construcion des disciplines scolaires. Revue Educacion e Francophonie. v. XXVIII, n. 2, automne-hiver, 2000. Revue Virtuelle: Disponível em: <http://www.acelf.ca/revue>. Acesso em: 30 mar. 2003. 
PERRENOUD, P. ( I 996). Ensinar: agir na urgência, decidir na incerteza. Porto Alegre: Artmed Editora, 2001 .

PERRENOUD, P. Lê role de la formation à l'enseignement dans la construcion des disciplines scolaires. Revue Educacion e Francophonie. v. XXVIII, n. 2, automne-hiver, 2000. Revue Virtuelle: Disponível em: <http://www.acelf.ca/revue>. Acesso em: 30 mar. 2003.

TARDIF, M. Saberes profissionais dos professores e conhecimentos universitários: elementos para uma epistemologia da prática profissional dos professores e suas consequências em relação à formação para o magistério. Revista Brasileira de Educação, Rio de Janeiro, n. I3, p. 5-24, jan./abr. 2000.

TARDIF, M. Saberes docentes e formação profissional. Petrópolis, RJ: Vozes, 2002.

Recebido: 23 dez. 2009 Aprovado: 21 jul. 2010

Endereço para correspondência: José Ângelo Gariglio

Rua Cachoeira do Campo, n 324, Apto. 502 Calafate - Belo Horizonte - Minas Gerais

CEP: $30480-180$ 